\title{
Editorial
}

\section{Enfoques históricos de la enseñanza en la Administración para la formación de la identidad enfermera}

\author{
Historical approaches to the teaching of the \\ Administration for the formation of the nurse's \\ identity
}

\section{Enfoques históricos do ensino de Administração para a formação identitária do enfermeiro}

\author{
Genival Fernandes de Freitas ${ }^{1}$, Magali Hiromi Takashi² e Fábio \\ Soares de $\mathrm{Melo}^{3}$ \\ ${ }^{1}$ Professor Titular do Departamento de Orientação Profissional da Escola de \\ Enfermagem da Universidade de São Paulo-Brasil. Correo electrónico: genivalf@usp.br \\ ${ }^{2}$ Doutora em Ciências do Programa de Pós-Graduação em Gerenciamento em \\ Enfermagem da Escola de Enfermagem da Universidade de São Paulo. Correo \\ electrónico:magalitakashi@usp.br
}

\begin{abstract}
${ }^{3}$ Mestrando em História do Programa de Pós-Graduação em Gerenciamento em Enfermagem da Escola de Enfermagem da Universidade de São Paulo. Correo electrónico: fabio.soares.melo@usp.br

Cómo citar este artículo en edición digital: Freitas, G.F., Takashi, M.H., E Melo, F.S. (2019). Enfoques históricos do ensino de Administração para a formação identitária do enfermeiro. Cultura de los Cuidados (Edición digital), 23(53). Recuperado de http://dx.doi.org/10.14198/cuid.2019.53.01

Correspondencia: CEscola de Enfermagem da USP. Av. Dr. Enéas de Carvalho Aguiar, 419. Sala 112. CEP: 05403-000. São Paulo- SP

Correo electrónico de contacto: genivalf@usp.br

Recibido: editorial invitada; Aceptado: editorial invitada
\end{abstract}

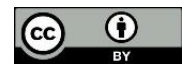

\section{ABSTRACT}

This editorial has the objective of reflecting on the historical approaches of teaching in administration for the formation of the nurse identity. Various historical documents have been used that collect relevant information on nursing in general and on nursing administration.

Keywords: History of nursing, nursing administration, nursing identity.

\section{RESUMO}

Este editorial tem como objetivo refletir sobre as abordagens históricas do ensino em administração para a formação da identidade do enfermeiro. Diversos documentos históricos foram utilizados para coletar informações relevantes sobre a enfermagem em geral e sobre a administração de enfermagem.

Palavras-chave: História da enfermagem, 
administração em enfermagem, identidade em enfermagem.

\section{RESUMEN}

Esta editorial tiene el objetivo de reflexionar sobre los enfoques históricos de enseñanza en administración para la formación de la identidad enfermera. Se han empleado diversos documentos históricos que recogen información relevante sobre enfermería en general y sobre administración de enfermería.

Palabras clave: Historia de la enfermería, administración en enfermería, identidad enfermera.

Construir uma reflexão sobre este tema tornou-se um desafio para nós pois estabelecer uma ponte entre Administração e Identidade Profissional da Enfermagem aparentava ser algo impensável tendo em vista que essência da enfermagem é o cuidado, algo aparentemente muito distante do ato de administrar.

Uma primeira indagação suscitada diz respeito a possível correlação dos estudos em Administração com os estudos em Enfermagem sem que se corra o risco de desvirtuar a essência do que é ser enfermeiro. Questão a nosso ver ainda bastante pertinente tendo em vista que alguns estudos, como por exemplo um realizado em 1999 intitulado «Concepção das alunas sobre o ensino da disciplina Administração Aplicada à Enfermagem no curso de graduação na Escola de Enfermagem da USP» revelou a incerteza daquele grupo de alunas de graduação quanto à real necessidade e quanto ao verdadeiro significado da Administração no trabalho da enfermeira. Este mesmo estudo ainda apontou para outro entrave, envolvendo esta disciplina, que era ensinada de forma clássica/tradicional e obsoleta, sendo consenso entre as alunas que este modelo constitui-se em um obstáculo para a fluência da capacidade crítica e racional da prática administrativa. Segundo a autora do estudo estes achados convergem para uma crise de identidade.

Contradições como essas apontadas acima envolvendo o ensino de Administração na enfermagem podem sugerir-nos a presença de uma lacuna a ser preenchida com base na pesquisa histórica que consiste em, segundo Lakatos e Marconi (2001), «[...] investigar acontecimentos, processos e instituições do passado para verificar a sua influência na sociedade de hoje $[\ldots .]$.$» .$

Pensar a questão da gênese e incorporação do saber administrativo em enfermagem nos remete aos primórdios de sua profissionalização, meados do século XIX, pois Florence Nightingale ao definir o que era ou não enfermagem, em Notas sobre Enfermagem (1859), já discutia sua dimensão ético-política delineando elementos administrativos do saber e do fazer da enfermeira.

Em estudo realizado por Freitas (2011) no qual discutiu-se as aproximações entre os livros escritos por José Bueno y González e por Florence Nightingale, sucessivamente, El arte de enfermería (1833) e Notas sobre Enfermagem (1859), ficou evidenciado que a origem do saber administrativo em enfermagem remonta a estes escritos, nos quais a prática assistencial e gerencial envolvendo o cuidado teve os primeiros registros.

A pesquisa revelou, também, inquietudes já existentes na época da elaboração dos textos acima citados que correlacionam Administração e Enfermagem, a saber: o que é e o que faz o enfermeiro (atribuições); as relações entre enfermeiros e médicos; a 
definição do espaço de atuação do enfermeiro; a questão do hospital como lócus do saber e das práticas não só dos médicos, mas também dos enfermeiros; o esquadrinhamento de saberes e de práticas de médicos e enfermeiros no contexto do século XIX na Europa, particularmente, Espanha e Inglaterra.

Florence Nightingale foi grande influenciadora na Administração em Enfermagem, proporcionou transformações por suas ideias inovadoras a frente de seu tempo (Formiga, Germano, 2005). Contudo pensar a enfermagem sob a ótica da Administração antecede a Florence e remonta a José Bueno y González, quando em 1833, já discutia sobre a temática, contudo por dificuldades de acesso ao público em geral sua obra ficou inacessível por muitos anos no mosteiro onde foi produzida (Oguisso, 2014).

O primeiro programa de ensino da enfermagem, que se tem registro na história, foi criado na Escola de Enfermagem do Hospital Saint Thomas, em Londres, na segunda metade do século XIX, por Florence Nightingale cujas características mais ressaltantes eram conhecimento e capacidade administrativa do cuidado. Seus primeiros registros de Administração Hospitalar, foi escrito em seu livro Notas sobre Enfermagem, uma obra que descreve como a assistência básica de enfermagem deve ser conduzida, independentemente do tipo de paciente. Posteriormente, o modelo Nightingaleano foi incorporado em outros cursos de enfermagem pelo mundo afora dando início a era da Enfermagem Moderna.

No Brasil, o ensino da administração teve início em 1923 com a criação da Escola de Enfermeiras do Departamento Nacional de Saúde Pública (DNSP) cujo currículo era composto por dezesseis disciplinas e entre elas Administração Hospitalar e Serviço
Administrativo Hospitalar (Formiga,

Germano, 2005).

No tocante ao ensino da Administração, entre 1960 e 70, foram introduzidas as teorias de Taylor e Fayol adaptadas ao trabalho de enfermagem e as necessidades da profissão transformando o ensino de Administração em Enfermagem: a Administração Científica, influenciado por Taylor, e a Teoria Clássica da Administração, influenciada por Fayol, sendo esta primordial para a organização hospitalar no Brasil. (Trevisan, 1988). A partir destas influências o ensino da Administração em Enfermagem sofreu uma divisão entre Científica cuja abordagem concentrou-se, especificamente, no cuidado e nas técnicas de Enfermagem, e a Clássica cujo enfoque centrou-se na organização e gerenciamento dos serviços de Enfermagem. Fayol foi um grande influenciador para o ensino para a Enfermagem e para a construção de uma identidade da enfermeira, pois por meio de suas teorias, estabeleceram os princípios da boa administração, sendo dele a clássica visão das funções do enfermeiro: organizar, planejar, coordenar, comandar e controlar.

O preparo para a liderança se tornou um objetivo esperado quando se trata da maioria dos programas de educação em Enfermagem, tendo em vista que a formação do enfermeiro é voltada com a junção de conhecimentos e técnicas adquiridos para o exercício da profissão como atenção à saúde, tomada de decisões, comunicação, educação permanente, administração, gerenciamento e todo conhecimento técnico científico para a assistência e cuidado de Enfermagem em todos os níveis (Lazoni, Meirelles, 2011).Partindo desta premissa, o processo construção da identidade do enfermeiro no processo de gerir e liderar uma equipe de saúde conduziu para o desafio de alcançar o 
equilíbrio entre a capacidade e o conhecimento para que sejam alcançadas todas as metas estabelecidas no sentido de otimizar todo e qualquer tipo de serviço, com ênfase no processo assistencial (Fradique, Mendes, 2013).

A liderança vem sendo trabalhada, historicamente, desde o início do ensino da Administração em Enfermagem, função essa primordial para a administração e a organização tanto na gestão de recursos humanos quanto na gestão de recursos materiais, físicos e ambientais. Contudo, as estruturas organizacionais das instituições de assistência contemplam, o modelo de administração clássica, onde a hierarquia exerce um papel dominante na divisão do trabalho. O enfermeiro passa a ser visto como um modelo central de poder e tomada de decisão acerca da assistência do cuidado (Willig, Lenardt, 2002). Todavia, é comum enfermeiros ainda consideram gerenciar e cuidar como atividades dicotômicas e incompatíveis em sua realização e estabelecem uma diferença entre cuidado direto e cuidado indireto, valorizando e entendendo como cuidado somente aquilo que depende de sua ação direta junto ao paciente (Erdmann, Backes, Minuzzi, 2007).

Tal dicotomia reforça a questão referente ao exercício da função administrativa mesclada por dúvidas, desentendimentos e incompreensões, ao produzir polêmicas entre o que se espera da enfermeira, na visão dos teóricos de Enfermagem, e o que se verifica na sua atuação cotidiana nas instituições de saúde (Trevizan, 1988).

O comportamento reproduzido por enfermeiros, na visão de Bourdieu, é interpretado como habitus, que atribui essa execução, frequentemente, a um caráter mecânico e inescapável no desenvolvimento do que se chama reprodução social. O que para Bourdieu, inúmeras vezes, a noção de habitus marca uma ruptura com a filosofia intelectual de toda ação e se funda no interior do caráter racional, que é verdadeiramente humana (Bourdieu, 1989).

Nessa perspectiva, o ensino de Administração em Enfermagem apresenta muitas características das abordagens Weber, Taylor e Fayol, no quesito de cumprimentos de normas, rotinas e tarefas, produzindo um habitus e reproduzindo mecanismos para atender o esperado por outros profissionais e instituições, deixando, muitas vezes, de priorizar as necessidades dos usuários dos serviços e ações de saúde gerando, por vezes, desmotivação e descontentamento dos trabalhadores de Enfermagem.

No contexto atual, as questões burocráticas, econômicas e legais das instituições de saúde, nos campos de atuação do profissional de Enfermagem, são demandadas das chefias de Enfermagem, que acabam por exercer o papel administrativo voltado para os interesses institucionais, sobrepondo ao interesse dos demais trabalhadores, caracterizando um processo de dominação, impessoalidade, relações hierarquizadas, ênfase na comunicação formal e cumprimento de indicadores e metas.

A gestão de Enfermagem ao longo do tempo vem evoluindo de acordo com as necessidades, demandas, ação e autonomia conquistados pelo enfermeiro em seus hábitos, refletindo em ações no cuidar, entretanto, o viés encontrado na realidade relacionada à dissociação da gerência e do cuidado advém do comportamento e relações humanas movidos pelos interesses capitalistas das instituições de saúde.

A experiência no cuidado integral deverá estar aliada à gestão da assistência de enfermagem, uma vez que o usuário responde de forma significativa ao cuidado, 
quando os enfermeiros são capazes de oferecer serviços de assistência segura e de qualidade ao cliente, considerando que na produção de trabalho do enfermeiro, cuidar e gerenciar são ações indissociáveis.
Enfermagem. Barueri (SP): Manole. Florence Nightingale, p. 57-97.

- Trevizan, M.A. (1988). Enfermagem hospitalar: administração e burocracia. Brasília (DF): Universidade de Brasília.

- Willig, M.H. \& Lenardt, M.H. (2002). A prática gerencial do enfermeiro no processo de cuidar. Cogitare Enferm, 7 (1), 23-29.

\section{REFERÊNCIAS}

- Bourdieu, P. O (1989). Poder simbólico. Rio de Janeiro: Bertrand Brasil.

- Erdmann, A.L., Backes, D.S. \& Minuzzi, H. (2007). Care management in nursing under the complexity view. Braz J Nurs, 8, 7(1). Disponível em http://www.uff.br/objnursing/\%20index.php/nursi ng/article/view/1033.

- Formiga, J.M.M. \& Germano, R.M. Por dentro da História: o ensino de Administração em Enfermagem. Rev. bras. Enferm, 58(2), 222-226. Disponível em http://www.scielo.br/scielo.php?script=sci_arttext \&pid=S0034-71672005000200019\&lng=en. $\quad$ DOI: http://dx.doi.org/10.1590/S0034$\underline{71672005000200019}$.

- Fradique, M.J. \& Mendes, L. (2013). Efeitos da liderança na melhoria da qualidade dos cuidados de enfermagem. Rev. Enf, serIII (10): 45-53. Disponível em http://www.scielo.mec.pt/scielo.php?script=sci art text\&pid=S0874-02832013000200006\&lng=pt. http://dx.doi.org/10.12707/RIII12133.

- Freitas, G.F. (2011). Gênese e incorporação do saber administrativo em enfermagem: análise do discurso a partir das obras El arte de enfermería e Notas sobre enfermagem [tese de livre-docência]. São Paulo: Escola de Enfermagem, Universidade de São Paulo.

- Lakatos, E.M. \& Marconi, M.A. (2001). Fundamentos da Metodologia Científica. 4. ed. rev. e ampl. São Paulo: Atlas.

- Lanzoni, G.M.M. \& Meirelles, B.H.S. (2011). Liderança do enfermeiro: uma revisão integrativa da literatura. Rev. Latino-Am. Enfermagem, 19 (3), 651-658. Disponível em http://www.scielo.br/scielo.php?script=sci_arttext \&pid=S0104-11692011000300026\&lng=en.

http://dx.doi.org/10.1590/S010411692011000300026.

- Leite, M.M.J. (1999).Concepção das alunas sobre o ensino da disciplina administração aplicada à enfermagem, no Curso de Graduação da Escola de Enfermagem da USP. R. Tec. Enferm. 2 (16), 30-34.

- Oguisso, T. (Org.). (2014). Trajetória histórica da 